\title{
The significance of citation impact indicators of research performance in the developing countries of sub-Saharan Africa
}

\author{
$J B A K U W A^{1}$
}

\begin{abstract}
This paper argues that Sub-Saharan Africa needs to produce more journals indexed by ISI Web of Science (WoS). Researchers from the region should also publish in other ISI indexed, reputable and high impact journals such as Nature and Science. Inevitably, this will make Sub-Saharan African researchers visible and globally competitive. The SubSaharan African region has only about 40 journals out of over 12000 journals that have been indexed by the ISI Web of Science (WoS). Arguably, ranking of universities across the globe and qualification for Nobel Prizes are determined by metrics-based evaluation of research performance. Sub-Saharan Africa is poorly represented on the world university rankings. The region has also produced only six Nobel Prize award winners from 1901 to 2010. In the same period, USA, UK and Germany produced 326, 116 and 102 recipients respectively. While there are some limitations on the use of citation indicators to evaluate research output, this researcher argues that citation impact indicators of research performance provide policymakers, researchers and funding agencies with an objective measure for assessing research performance and therefore are of great significance in the developing countries of Sub-Saharan Africa.
\end{abstract}

Key Words: bibliometrics, citation impact indicators, journal impact factor, research output, Sub-Saharan Africa, Web of Science (WoS), Scopus, Google Scholar

\section{Introduction}

Bibliometric indicators attempt to measure impact, visibility and quality of research output. The development of bibliometric indicators is thus key to evaluating performance of scientific research (see Van Leeuwen et al., 2001; Garfield, 2003). The bibliometric indicators mostly used to assess performance and influence of scientific research are the number of research articles (or publications) and citations (Moed, 2009). Citation impact indicators are important tools for measuring the quantity and quality of scientific research output. Inadvertently, quality and quantity of research have a significant impact on scholarship and the world at large. Science policy makers, managers and funding agencies make policy decisions based on citation impact indicators. Today, the journal impact factor ${ }^{2}$ is widely used

1 Japhet Bakuwa is a registered PhD student at Stellenbosch University's Centre for Research on Evaluation, Science and Technology, Private Bag X1, Matieland, 7602, South Africa.

Email: 16839889@sun.ac.za. Acknowledgement: Many thanks should go to the two anonymous reviewers whose comments I found tremendously helpful as I revised the manuscript. I also thank Helen J. van Niekerk of Transliterate for editing the paper thoroughly.

2 The journal impact factor is a measure of the total number of citations for each of the papers published in that particular journal during the previous 2 years divided by the total number of eligible articles within that particular period. It can be considered to be the average number of times published articles are cited by authors up to 2 years after publication (Garfield, 1979: 149). 
by researchers, science policymakers and funding agencies to assess impact and quality of research output.

The use of citation impact indicators as determinants of quality of research output have been heavily debated: some argue that they are a flawed measure of quality and should not be used, while others think that they should be refined to improve their accuracy of indicating the quality of research output (Seglen, 1997a; Moed, 2005; Seglen, 1997b; Williams, 2007). Simply put, there are some reservations about the use of metrics and quantitative indicators for evaluating research performance. The criticism against impact indicators notwithstanding, the researcher in this essay argues that citation impact indicators can be of use to developing countries of Sub-Saharan Africa.

\section{The use of citation impact indicators of research performance}

Bibliometrics measures the impact, visibility, and quality of scientific publications. In bibliometrics, citation impact indicators have been developed as tools assessing the performance of scientific research output. According to Tijssen (2003), citation impact indicators "disclose the actual scientific influence of papers on the outside world- a key indicator of research excellence from a user-oriented point of view" (Tijssen, 2003: 98). Some of the indicators used include: number of citations; number of citations per document; number of highly cited papers; number of uncited publications; number of citations received by a publication from other publications; number of publications; citations per publication rate, normalized by the average citation scores of corresponding journals during a specified time interval; average number of citations per indexed publication(s) produced by an entity within a specified time interval; number of h-index which is a single measure of quantity (publications) and impact of the research output; relative citation rate (RCR) i.e. citations of documents as compared with their publication journal, etc.

There are a number of databases that index scientific publications on the basis of number of citations. These databases include Thomson Reuters Web of Science (WoS), Elsevier's Scopus and Google Scholar. Suffice to say, each of these databases has its merits and demerits. In this discussion reference will be made to Thomson Reuters WoS because it is generally considered to be the world's largest and most reliable citation database covering over 12000 of the highest impact journals worldwide across more than 250 disciplines (http://thomsonreuters.com). Since 1973 the Institute for Scientific Information (ISI) has been producing the impact factor in the Journal Citation Reports (JCR). The general perception is that if a journal is not indexed by WoS, it means that no impact factor is available (Pendlebury, 2009).

By means of citation analysis and the impact factor, the Thomson Reuters' Institute for Scientific Information (ISI) Web of Science (Science Citation Index, Social Sciences Citation Index and Arts and Humanities Citation Index introduced in 1963, 1973 and 1978 respectively) and Elselvier (Publishers) Scopus databases have indexed a number of journals to signify the quantity and quality of research output. It is assumed that journals indexed by either ISI's Web of Science or Scopus are high impact journals as determined by these citation impact indicators. However, caution should be exercised when using these indicators as they may give a skewed picture of research performance. For instance, articles published in the natural and applied sciences tend to be cited more than those in humanities and social sciences. Since citation frequencies are output-dependent, field-dependent and time-lag 
dependent, it is important that citation frequencies should be normalized accordingly (Tijssen lecture, 2011, Stellenbosch).

One reason for the importance of citation impact indicators are that they can be used as a basis for making policy decisions. For instance, there has been a proposal in UK that research institutions should be funded based on their research performance as reflected through bibliometric indicators (Hobbs \& Stewart, 2006: 983). This proposal, however, is controversial, because in addition to aiding the assessment of scientific research output, citation analysis also contributes to the understanding of networking among researchers and the development of fields of study (Garfield 1979; Zitt \& Bassecoulard, 2008).

Another reason why citations are important is that they are used to rank journals based on the ISI impact factor and can also be a useful tool for establishing a relationship between papers, fields, authors or even journals (Jusoff, 2008). They can furthermore be used as a guideline in determining which individual researchers or institutions should be granted awards i.e., Nobel Prizes to (Garfield, 1979).

\section{Research performance in Sub-Saharan Africa}

Generally speaking, Sub-Saharan Africa's overall contribution to global science is steadily declining. In Tijssen's 2007 article assessing Africa's contribution to the worldwide research literature, he noted that Sub-Saharan Africa's contribution to global knowledge has fallen dramatically from 1\% share in 1987 to 0.7\% in 1996 (Tijssen, 2007: 304). However, over the last decade there has been an increase in Africa's research output. Pouris and Pouris (2009), in their analysis of the state of science and technology in Africa between 2000 and 2004, report that Africa produced 68945 publications in this time frame, representing $1.8 \%$ of the World's publications (Pouris \& Pouris, 2009: 301). 23335 of these 68945 publications were publications from the North African countries (Egypt, Morocco and Tunisia), 20762 were from South Africa and the rest from other African countries. This analysis further shows that Sub-Saharan countries are not contributing significantly to the world's publications, with the exception of South Africa. It should be noted that 40 South African journals are indexed in Thomson Scientific's Citation indexes (Mouton \& Gevers, 2009). It is worrisome to note that 47 countries in the Sub-Saharan African region are only contributing $1.8 \%$ to global science. This speaks volumes of the quality of journals (including research) of this region. Africans need have more journals indexed by ISI as this will ensure an international presence. Moreover, African researchers should be publishing in international high impact journals.

Sub-Saharan Africa's scientific research performance are reflected in three main areas: the number of African journals indexed by Thomson Reuters' ISI, the number of African universities listed on rankings of world universities and the number of African recipients of Nobel Prize laureates. These numbers are important because the ranking of journals, universities and researchers are based on the number of citations to publications. A discussion of these areas will follow.

\subsection{Citation impact indicators and African journals in ISI's Web of science}

Journals found in ISI's Web of Science are assumed to have a high impact factor. By implication articles that are published in ISI-journals are also assumed to have a high impact factor determined in part by the number of citations to articles within a particular journal. The more these articles are cited, the higher the publishing profile of the author is raised. In 
short, the quality of a journal is intimately connected to its impact factor. The higher the impact factors of a journal, the higher the quality of that particular journal is.

The number of African journals indexed by ISI's Web of Science is low compared to the total number of journals published in Africa. Only about 40 out of $250^{3}$ accredited South African journals were indexed by Web of Science as of 2009. Mouton and Gevers (2009) analysed South Africa's output in ISI journals and noted that most of the journals indexed in the ISI Web of Science are natural and health science journals. They observe that:

South Africa's output in ISI-journals has been dominated by the sciences (43$46 \%)$, followed by the health sciences (25-28\%) and engineering (10\%). The social sciences and humanities, combined, have produced between 9 and $11 \%$ of all outputs (Mouton \& Gevers, 2009: 58).

This means that the sciences contribute to about $90 \%$ of South Africa's output in ISIjournals. This picture is reversed when one analyses the output in non-ISI local journals, as pointed out by Mouton who claims that the social sciences and humanities represent about three quarters of the output in local non-ISI journals (all South African journals) (Mouton \& Gevers, 2009: 58). This means that the bulk of South Africa's non-ISI journals publish social sciences and humanities articles. This is mirrored by the state of scientific publication output in Sub-Saharan Africa. Many African academics publish in local journals not indexed by ISI Web of Science instead of publishing in international journals. Understanding the reasons behind this trend is worth pursuing.

\subsection{Citation impact indicators and African recipients of Nobel Prize Laureates}

Policy making is only as good as the evidence used to formulate it. We live in an information age where credible knowledge is necessary for virtually every decision we make. Reliable information and metrics are the basis for science policy and strategic decision making in the world today. Thus, policy makers, science managers, and funding agencies use citation indicators to support research assessment decisions (Costas \& Bordons, 2007). Citation impact indicators can even determine the level of research and development of a particular country. This emphasises the importance of citation impact indicators for Sub-Saharan African countries.

Citation impact indicators are also used to reward individuals for their distinguished contribution to the knowledge base. Nobel Prize Organizations, for example, select recipients of prizes on the basis of their remarkable achievements in literature, physics, chemistry and physiology or medicine. This decision is mainly based on the number of citations in high impact journals of their ground-breaking research in respective fields (//nobelprize.org; Garfield, 1979). Since 1901 (the year these awards were first given) Sub-Saharan African has only produced 18 Nobel Prize winners eight of whom are Nobel Peace Prize winners and 10 are Nobel Prize winners in literature, physiology or medicine and physics. Six out of the 10 Nobel Prize winners were from the Sub-Saharan Africa. This means that from 1901 to 2010, Sub-Saharan Africa has produced only six Nobel Prize winners who have contributed to two fields, namely three in literature and three in medicine. Over the same period USA, UK and Germany have produced 326, 116 and 102 recipients respectively. If developing countries of

3 As of 2014 the South Africa Department of Higher Education and Training has accredited

274 local journals. See www.dhet.gov.za 
Sub-Saharan Africa are to produce more recipients of the prestigious Nobel Prizes then citation impact factors, derived from journals indexed by Thomson Reuters' Web of Science, should be taken seriously. African academics and researchers need to improve their research output to be globally competitive.

\subsection{Citation impact indicators and African universities on world rankings}

It is well known that citation impact indicators play an important role in the ranking of universities worldwide. Three of the institutions that use citation impact indicators as part of a criterion to rank world universities are: the Times Higher Education, Shanghai's (ARWU) and the Leiden University. ${ }^{45 \%}$ African universities are conspicuously absent on world rankings. For instance, the 2010-2011 Times Higher Education show University of Cape Town (RSA) and Alexandria University (Egypt) as the only African universities that appear in the 'top 150', ranking $107^{\text {th }}$ and $147^{\text {th }}$, respectively, among the world universities. If Alexandria is not considered, it means that only one university in the Sub-Saharan Africa appears on this ranking. The University of Cape Town appears on the Leiden University ranking (161 ${ }^{\text {st }}$ ). The 2010 Shanghai (ARWU) has only six African universities in the 'top 500', with the University of Cape Town in the bracket group of 'top 300' while the University of Witwatersrand and the University of KwaZulu-Natal both are in the bracket group of 'top 400'. Thus, only three South African universities represent the whole SubSaharan African region on world university rankings - a region that has hundreds of so called research universities.

There could be two possible explanations for the poor showing of African universities on world rankings. The first is that Sub-Saharan African universities do not have research influence on world knowledge base. These institutions use publications and citations as indicators of scientific worth (Frey \& Rost, 2010: 3). It means that African academics do not publish adequately in high impact journals. Certainly, African academics publish relevant research, but they do so in local journals with a limited global exposure which are not indexed by ISI's Web of Science. Understandably, some of these local journals are published in the local languages because they target the local audience, whereas the Web of Science targets the international audience and hence is biased towards the English language. For a university to appear on Shanghai ranking, researchers need to publish in high impact journals such as Nature and Science. ${ }^{7}$ The second explanation for the poor performance of African universities on world ranking is that the Web of Science - with a very good coverage of basic (or natural) and applied sciences - is not focused on social science, humanities and arts journals. Arguably

4 2010-2011The Times Higher Education world university ranking. Available at: http://www.timeshighereducation.co.uk/world-university-rankings/2010-2011/top-200.html. Accessed on 19 May 2011.

52010 Shanghai's (ARWU) has 500 universities on its ranking. Available at: http://www.arwu.org/ARWU2010.jsp. Accessed on 19 May 2011.

62010 Leiden University ranking. Available at: http://www.topuniversities.com/institution/leiden-university. Accessed on 19 May 2011.

Nature and Science are highly reputed science journals. According to ARWU papers published in these two high impact journals account for $20 \%$. For institutions specialised in humanities and social sciences such as London School of Economics, this criterion is not considered. Instead, the weight is relocated to other indicators. Available at: http://www.arwu.org/ARWUMethodology2010.jsp. Accessed 
some African academics, especially from the social sciences, humanities and arts disciplines, have authored books and chapters in books which are not covered by ISI's Web of Science. The Times Higher Education uses a normalised citation impact to assess a university's research influence. ${ }^{8}$ Overall, it is clear that citation impact indicators should be taken seriously by universities in the Sub-Saharan region if they would like to be ranked among the best in the world. African academics should increase their publications in high impact journals to ensure that the number of citations is significant to put their research universities on the world map. Certainly it has to be acknowledged that high quality research output in the Sub-Saharan African region has been hampered by a plethora of factors. Inadequate government funding to public universities in particular, has led to inadequate library and laboratory facilities, an inability to subscribe to journals, limited mobility and poor education. Simply put, the environment in these resource poor Sub-Saharan African universities is not conducive to high quality research performance.

\section{The downside of using metrics and quantitative indicators in evaluating research performance}

The use of bibliometric indicators to assess scientific research performance has generated a considerable amount of discussion (Garfield, 1979: 359). Three of these indicators are the journal impact factor (IF), the Hirsch index (H-index) and the Eigen factor. The journal impact factor is currently used by science policymakers, researchers and funding agencies to assess impact and quality of research output. In spite of the perceived advantages, science policymakers and research funders need to be aware of the limitations, misuse and negative effects of metrics-based evaluation of research performance (Schoonbaert \& Roelants, 1996; Amin \& Mabe, 2000; Bordons et al., 2002; Leydesdorff, 2008; Pendlebury, 2009). The sections that follow discuss some of the problems related to the use of metrics and quantitative indicators for evaluating research output.

\subsection{Language biases in indexing journals}

The value of impact indicators of research performance is dependent on the inclusion or exclusion of research publications in the WoS databases (Van Leeuwen et al., 2001). Language of scientific publications plays a key role in the inclusion or exclusion of a publication. There is empirical evidence that most of the journals indexed by ISI WoS are English.

Obviously, there are some journals of high quality and importance that are not covered by ISI's Web of Science simply because they are not written in English. For instance, a significant number of journals in Germany, France, Spain, Switzerland and even Africa are not indexed on the basis of their language. Since these journals are not indexed, this affects the impact factor scores of individual researchers, institutions and countries. Incidentally, the impact factor measures of English journals in mainly US and UK far outweigh those of nonEnglish language journals (Van Leeuwen et al., 2001). As a matter of fact, the ISI WoS

8 The Times Higher Education ranks universities on the basis of their research influence measured by the number of times a university's published work is cited by academics. This is the largest measure of the broad rankings categories which accounts for $32.5 \%$ of the overall score. Available at: http://www.timeshighereducation.co.uk/world-university-rankings/20102011/analysis-methodology.html\#citations. Accessed on 20 May 2011. 
databases are dominated by American publications (Coryn, 2006: 118). This means that the impact factor measure does not reflect all scientific research output in a particular country. It would be naïve of policymakers to compare and evaluate national science systems solely on the basis of the impact factor as provided by JCR. Simply put, the journal impact factor is not a good measure of research output of institutions or countries.

According to Van Leeuwen and colleagues (2001) science policymakers need to acknowledge that, although English is considered to be the most important language of science, other languages are also used (Van Leeuwen et al., 2001: 336). In their scathing criticism of the use of the impact factor to evaluate research performance, Hecht and colleagues (1998) claim that the impact factor has clearly become a key marketing tool where some journals are being promoted at the expense of others. They think that the 'impact factor' is misnamed, misleading and hence misused by science policymakers (Hecht et al., 1998: 77).

\subsection{Discipline-related biases}

The ISI Web of Science coverage is also biased towards the science disciplines. The WoS has a multidisciplinary coverage of over 12000 journals worldwide across more than 250 disciplines (http://thomsonreuters.com). Web of Science has excellent coverage of the sciences, particularly of molecular biology and biochemistry, biological sciences related to humans, clinical medicine, physics, astronomy and chemistry (Schoonbaert \& Roelants, 1996). The coverage for social sciences and arts and humanities is moderate. The Science Citation Index (SCI) has 8500 journals across 150 science disciplines. The Social Sciences Index (SSI) has 3000 journals across 55 social sciences disciplines while the Arts and Humanities Citation Index (AHCI) has 1700 journals across 56 disciplines. The foregoing suggests that science disciplines dominate coverage of over $60 \%$ in the $\mathrm{WoS}$ databases. While most physical science publications are in journal format, the social sciences and the arts and humanities are mostly published in books and therefore not indexed by ISI, negatively affecting citation counts and impact factors.

It is also worthwhile to note that citation patterns are discipline-linked and this affects absolute citation counts and journal impact factors (Schoonbaert \& Roelants, 1996), the latter which depends on the research field (Seglen, 1997). The science disciplines, like molecular biology and biochemistry, publish and cite more than the other disciplines. $75 \%$ of social science publications are not even cited once, while the arts and humanities publications are worse off with an average of $98 \%$ publications that are not cited (Schoonbaert \& Roelants, 1996). It also seems that citation to social sciences and humanities publications only occurs long after the publication date. This affects the number of citations in these disciplines. The exclusion of social sciences and humanities journals in the WoS databases means that they will always have a low impact factor. Ironically, the impact factor is what is used to index journals in the WoS databases. This is why the journal impact factor alone should not be a basis for making science policies.

\subsection{Research quality and metrics-based evaluation of research performance}

The impact factor is increasingly becoming a measure for determining quality of research. It has become standard practice for science policymakers and research funders to use the impact factor as a basis for policy decisions (Moed, 2005). For instance, some journals such as Nature and Science are considered as high quality journals because they have high a impact factor. By implication, all the papers that are published in these two high impact journals are also of 
high quality. Suffice to say that a high impact factor does not necessarily denote a high quality journal and conversely, a low impact factor does not necessarily denote a low quality journal. The number of citations has become a major determinant for research rankings. But citations do not measure research quality. This implies that rankings do not reflect research quality, but rather research quantity; they merely show the position or significance of researchers (Frey \& Rost, 2010: 2). Some studies have criticized the impact factor as being too simple a measure that does not capture enough of the multidimensional phenomena of a journal's influence and quality (Hobbs \& Stewart, 2006; Seglen, 1997; Coryn, 2006; Williams, 2007; Pendlebury 2009; Frey \& Rost, 2010).

It is important to understand that it is only possible to obtain an impact factor if publications are indexed by ISI WoS. Not all research publications are, however, indexed by ISI WoS and the criterion for inclusion or exclusion of publications in ISI WoS is hugely biased as some journals, institutions and countries are favored above others. If some publications are not indexed and the impact factor for journals produced by JCR yearly determines quality of research, then the impact factor is indeed a flawed measure of research quality. Moed (2005) is of the view that that citation impact has limited value as an indicator of research quality (Moed, 2005: 81). The best way to evaluate quality of research is by combining bibliometric indicators with peer reviews (Moed, 2009).

\subsection{Relevance of scientific research vs number of citations}

Although bibliometric and other citation indicators can measure the influence scientific research has, it is not a measure of the relevance or usefulness of research. A journal with a low impact factor, for example, may be very relevant within its social context. In other words, low impact factor does not necessarily denote that the journal is irrelevant. In South Africa 40 out of 274 journals accredited by the Department of Higher Education are indexed by ISI WoS. Thus, over 200 journals (mostly in social sciences and arts and humanities) are assumed to have a low impact factor; hence they are not indexed. However, this does not mean that they are irrelevant when it comes to solving certain socio-economic problems in South Africa. Some of these journals are published in national languages, i.e. Afrikaans. It would be naïve to discard these journals as useless. Bibliometric indicators do not capture this aspect of research performance.

\section{Peer review or metrics-based evaluation of research output}

It is necessary to assess research performance. One assessment method is using metrics and quantitative indicators. This has merits and demerits. In the light of the limitations and criticisms discussed in this paper, how should research performance then be assessed? Some researchers suggest that we should disregard impact factors and use peer reviews (Williams, 2007). Others wonder to what extent peer reviews are objective (Garfield 2003; Schoonbaert \& Roelants, 1996). Schoonbaert and Roelants (1996) is of the opinion that peer reviews are prone to all kinds of biases, such as sympathy, antipathy, nepotism, in-house bias, 'old boys' networks, filling up socio-political quota, etc. Seglen (1997b) has aptly argued that there is a need for more qualified experts to read and evaluate the contents of publications. This should complement the use of metrics. He quotes Sidney Brenner who once said: "What matters absolutely is the scientific content of a paper, and nothing will substitute for either knowing or reading it." (Seglen, 1997a: 497). Indeed, an assessment of the contents of papers is important as this vindicates whether the journal impact factor really determines the quality of one's research. 


\section{The problem of using citation impact indicators to measure research quality}

One of the contentious issues in the study of bibliometrics is about the use of citation impact indicators to measure research quality. Some analysts argue that citations are a good measure of research impact rather than quality (Seglen, 1997b; Moed, 2005; Williams 2007). Seglen argues that evaluating quality of research output is a very difficult task which has no standard solution (Seglen, 1997b: 497). Moed (2005) thinks that as much as citation impact can be understood as an indicator of research quality, it does not give a comprehensive picture of quality (Moed, 2005: 81). In other words, one needs a different set of tools to measure research quality.

The argument can be extended further by proposing that the use of journal impact factors to determine the quality of a journal is questionable and that a high impact journal is not necessarily a high quality journal. For instance, one can claim that Science and Nature are high impact journals, but this does not guarantee that they are high quality journals.

Measuring quality or excellence of research is a mammoth task. Tijssen (2003) points out that the notion of 'research excellence' (good quality science) has not been clearly defined as it is complex and multi-faceted, and has aptly argued that assessment of research excellence requires "a systematic and interactive approach, combining multiple perspectives and stakeholders, while incorporating a wide range of information sources and quantitative indicators within the analytical framework of a "scoreboard"” (Tijssen, 2003: 91). This means that one cannot use a single indicator i.e., journal impact factor, to assess the quality of a journal.

Others have suggested that the quality of research is accurately assessed when metrics (including bibliometric indicators) are combined with peer reviews (Frey \& Rost, 2010; Moed, 2009).

The above observation has far reaching implications. It implies that not all journals indexed by ISI Web of Science or Scopus are of high quality, and conversely, not all journals not indexed by these databases are of low quality. But equally vexing is the implication that all decisions made by science policy makers based on the numbers of citations are questionable; this, of course, includes decisions to rank world universities, award Nobel Prize laureates and index journals in Web of Science or Scopus. A question that remains to be answered is: Does Sub-Saharan Africa produce high quality journals that are not indexed by ISI's Web of Science?

\section{Conclusion}

To sum up, Sub-Saharan Africa's contribution to global science, now at $1.8 \%$, leaves a lot to be desired. Partly, this is because not many African journals are indexed by ISI Web of Science. This has contributed to Sub-Saharan African countries' poor showing on the global map as reflected in the number of recipients of Nobel Prize awards, position and number of African universities on world university rankings and number of African journal articles indexed by Web of Science. African academics and institutions need to improve on both impact and quality of research output to be globally competitive. One measure of research impact and quality is the number of citations. There are some bibliometricians who think that citations alone cannot fully measure research quality, but that metrics should be combined with peer reviews. They argue that the quality of research is best assessed by 
qualified experts. Nonetheless, it is this researcher's opinion that citation impact indicators are useful and important, even in the developing countries of Sub-Saharan Africa.

\section{References}

Amin, M. \& Mabe, M. 2000. Impact Factors: Use and abuse. Perspectives in Publishing 1:1-6.

Bordons, M. et al. 2002. Advantages and limitations in the use of impact factor measures for the Assessment of research performance in a peripheral country. Scientometrics 53.2:195-206.

Centre for Science and Technology Studies (Leiden University). 2010. Leiden Ranking 2010. Available at: http://www.topuniversities.com. Accessed 20 May 2011.

Coryn, C. L. S. 2006. The use and abuse of citations as indicators of research quality. Journal of MultiDisciplinary Evaluation 3.4: 115-120.

Costas, R.and M. Bordons. 2007. The h-index: Advantages, limitations and its relation with other bibliometric indicators at the micro level. Journal of Informetrics 1: 193-203. Available online at www.sciencedirect.com. Accessed on 21 May 2011.

Frey, B. S. \& Rost, K. 2010. Do rankings reflect quality? Journal of Applied Economics 13.1: $1-38$.

Garfield, E. 1979. Is citation analysis a legitimate evaluation tool? Scientometrics 1.4: 359375.

2003. The Meaning of the impact factor. International Journal of Clinical and Health Psychology 3.2: 363-369.

Hecht, F. et al. 1998. The Journal "Impact Factor": A misnamed, misleading, and misused measure. Cancer Genet Cytogenet 104: 77-81.

Hobbs, F. D. \& Stewart, P. M. 2006. How should we rate research? BMJ 332: 983.

Jusoff, H. K. 2008. In search of best impact and citation indexed journals towards achieving goals of universities. $J$ Biochem Tech 1.1: 23-29. Available online at: jbiochemtech.com/index.php/jbt/article/view. Accessed on 20 May 2011.

Kostoff, R. N. 1998. The use and misuse of citation analysis in research evaluation. Scientometrics 43.1: 27-43.

Leydesdorff, L. 2008. Caveates for the use of citation indicators in research and journal Evaluations. Journal of the American Society for Information Science and Technology, 59.2: 278-287.

Moed, H. F. 2005. Citation Analysis in Research Evaluation. Dordrecht: Springer.

2009. New developments in the use of citation analysis in research evaluation. Arch. Immunol. Ther., 57: 13-18. Available at: http;//iopress.metapress.com. Accessed on 20 May 2011. 
Mouton, J. \& Gevers, W. 2009. Introduction. In R. Diab and W. Gevers (eds.). The State of Science in South Africa. Pretoria: Academy of Science of South Africa, 2009.

The Nobel Organizations. Available at: http://nobelprize.org/nobel_organizations/ Pendlebury, D. A. 2009. The use and misuse of journal metrics and other citation indicators. Arch. Immunol. Ther. Exp. 57: 1-11.

Pouris, A. \& Pouris, A. 2009. The state of science and technology in Africa (2000-2004): A scientometric assessment. Scientometrics 79.2: 297-309.

Schoonbaert, D. \& Roelants, G. (1996). Citation analysis for measuring the value of scientific publications: quality assessment tool or comedy of errors? Tropical Medicine and International Health 1.6: 739-752.

Seglen, P. O. 1997a. Why the impact factor of journals should not be used for evaluating research. BMJ314: 498-502.

1997b. Citations and journal impact factors: questionable indicators of research quality. Allergy 52 (1997b): 1050-1056.

Shanghai Ranking. 2011. Academic Ranking of World Universities. Available at: http://www.arwu.org. Accessed on 20 May 2011.

Tijssen, R. J. W. 2003. Quality Assurance: Scoreboards of research excellence. Research Evaluation 12.2: 91-103.

2007. Africa's contribution to the worldwide research literature: New analysis perspectives, trends, and performance indicators. Scientometrics 71.2: 303-327.

. 2011. Introduction to scientometrics and bibliometrics. Lecture at Stellenbosch University. Stellenbosch University, March 2011.

Thomson Reuters. 2011. Thomson Reuters' Web of Science. Available at: http://thomsonreuters.com. Accessed on 24 February 2014.

The Times Higher Education. 2011. The World University Rankings 2010-2011. Available at: http://www.timeshighereducation.co.uk/world-university-rankings/20102011/top-200.html. Accessed on 21 May 2011.

van Leeuwen, T. N. et al. 2001. Language biases in the coverage of the Science Citation Index and its consequences for international comparisons of national research performance. Scientometrics 51.1:335-346.

Williams, G. 2007. Should we ditch impact factors? BMJ 334: 568.

Zitt, M. \& Bassecoulard, E. Challenges for scientometric indicators: data demining, knowledge-flow measurements and diversity issues. Inter-Research 8 (2008): 49-60.

Available online at: www.int-res.com. Accessed on 21 May 2011. 